\title{
ES EL PSICOLOGISMO REFUTABLE SEGÚN FREGE?
}

\section{Is psychologism refutable according to Frege?}

\author{
Mario Ariel González Porta \\ Doutor em Filosofia pela "Westfälische Wilhelms Universität Münster, professor titular da Pontifícia \\ Universidade Católica de São Paulo (USP), São Paulo, SP - Brasil, e-mail: mariopor@ pucsp.br
}

\section{Resumen}

Contrariamente a lo que sostiene una opinión ampliamente difundida, Frege considera que el psicologismo es refutable y ha ofrecido al menos dos argumentos en tal sentido. Con uno de ellos nos ocuparemos en el presente artículo. El análisis del mismo habrá de evidenciar que en él se contiene un notorio paralelo con una de las líneas de argumentación desarrolladas por Husserl, de tal forma que no tiene sentido admitir un intento de refutación del psicologismo en Husserl y negarlo en Frege.

Palabras-claves: Psicologismo. Frege. Husserl.

\begin{abstract}
Contrary to a widespread opinion, Frege considers psychologism to be refutable and offered at least two arguments in that sense. The present paper deals with one of them. Its analysis will bring forth that it is in a notable parallel with one of the argument lines
\end{abstract}


developed by Husserl, in such a way that it is nonsensical to admit an attempt to refute psychologism in Husserl and deny it in Frege.

Keywords: Psychologism. Frege. Husserl.

\section{L - Logik}

GGA - Grundgesetze der Arithmetik. Begrifflich abgeleitet.

GA - Die Grundlagen der Arithmetik.

$\mathrm{RC}$ - Rezension von H. Cohen.

LU - Logische Untersuchungen.

\section{INTRODUCCIÓN}

Según una interpretación sustentada por Føllesdall en su trabajo pionero sobre Frege, existe una diferencia fundamental en la crítica al psicologismo de Frege y Husserl, pues, en tanto para Frege el psicologismo no es refutable con medios puramente lógicos, para Husserl esto sí es posible. ${ }^{1}$ No obstante, si Husserl, a diferencia de Frege, cree encontrarse en condiciones de refutar el psicologismo, esta pretensión es ilegítima. Un análisis de sus argumentos muestra que, en última instancia, los mismos remiten a una apelación a la evidencia. En suma, en su aclamada crítica del psicologismo, de hecho, Husserl no ha avanzado un paso más allá de Frege².

La interpretación de Føllesdall no ha permanecido sin consecuencias. Por un lado, ella ha sido retomada por Sukale, quien le ha otorgado un significativo desarrollo (sobre todo en el sentido de una explicitación mayor de la tesis de Frege y una profundización de su comparación con Husserl, diferenciándose únicamente en que no concede a la evidencia el rol monopólico que le asigna Føllesdall), por otro, ella aún se encuentra vigente, como lo evidencia uno de los últimos y más significativos análisis de la polémica antipsicologista de autoría de Martin Kusch ${ }^{3}$.

Føllesdall: Husserl and Frege, p. 35 y 49-50.

2 Føllesdall ha abierto un largo camino de comentaristas que lejos de ver en la crítica del psicologismo de Husserl una pieza de inestimable valor filosófico, han insistido en demostrar sus debilidades, como Meiland, Sukale, Fröhlich, etc. Véase bibliografía.

3 Véase bibliografía. 
Los apuntamientos correctivos de Mohanty, extremadamente parcos y circunstanciales ${ }^{4}$, no han encontrado eco alguno e, incluso, el propio Mohanty no vuelve sobre los mismos en sus trabajos posteriores. Estos apuntamientos, por otra parte, son insuficientes porque el carácter parcial de la citación efectuada (no menos que las breves consideraciones que la acompañan), dejan dudas al respecto de cómo este estudioso entendió el argumento fregueano que pretende resaltar.

En las líneas que siguen me propongo probar,

1) que Frege no afirma expresamente que el psicologismo es irrefutable;

2) que, de hecho, Frege ofrece en su texto por lo menos dos intentos de refutación;

3) que en uno de estos intentos (que es el único con el que, por razones de espacio, hemos de ocuparnos en este trabajo $)^{5}$ se constatan similitudes en las estrategias argumentativas de Frege y Husserl, pudiéndose establecer un paralelo entre ambas;

4) que, dado lo anterior, no existe pues, en lo que respecta a la refutación del psicologismo, el hiatus entre Frege y Husserl que se ha pretendido.

Indicados los objetivos, es ahora importante establecer los límites en el marco de los cuales habremos de movernos. No pretendemos ni responder a las objeciones hechas a Husserl, ni, lo que dado el contexto referido es necesariamente correlativo, probar que el argumento de Frege estaría libre de toda dificultad si fuera sometido a críticas como aquellas a las cuales han sido sometidos los husserlianos.

\section{ANÁLISIS DEL TEXTO DE BASE}

Empecemos por revisar la lectura del pasaje de "Las leyes fundamentales de la aritmética", en el cual Føllesdall basa su interpretación.

\footnotetext{
4 Husserl and Frege, p. 31-32

5 Del otro argumento aludido nos ocupamos en un artículo de próxima aparición: “A crítica de Frege ao idealismo em "Der Gedanke"”.
} 
Si consideramos el texto fregueano en su contexto, el momento central del mismo consiste en cuestionar el intento psicologista de una fundamentación extra-lógica de la lógica, lo cual implica asumir la pretensión de un punto de vista superior a la misma a partir del cual ésta puede ser validada. Contra esta pretensión Frege explicita el único sentido en el cual es viable una fundamentación de las leyes lógicas: ella sólo puede consistir en derivar una ley lógica de otra. Es en este contexto que Frege afirma que, cuando esto no es posible, no puede tener lugar una fundamentación, o sea, que, en última instancia, debemos admitir que llegamos a leyes lógicas que no pueden ser lógicamente fundadas.

En suma, en el marco de una oposición entre fundamentación lógica y extra-lógica de la lógica, Frege afirma que las leyes lógicas básicas no admiten fundamentación. En estos pasajes, no obstante, no hay nada, a nivel textual, que legitime atribuir a Frege la ulterior afirmación de que, por el motivo antes mencionado, el psicologismo es irrefutable. Atribuirle tal tesis es ya una interpretación, la cual sólo puede pretender basarse en razones de orden sistemático. La cuestión pasa ahora por determinar si éstas son suficientes.

No se puede dejar de conceder que, si la demostración de las leyes lógicas fuese el único camino para refutar el psicologismo, entonces tal refutación sería efectivamente imposible, pues ella necesariamente conduciría a un círculo vicioso o a una petición de principio ${ }^{6}$. Es obvio, que las leyes lógicas no pueden ser fundadas, porque toda fundamentación las presupone. Ahora, con lo anterior, meramente tenemos un condicional, y la verdadera cuestión es si la premisa debe ser necesariamente aceptada. ¿Acaso no será posible otro camino de refutación del psicologismo que no consista en demostrar la validez de la lógica? En efecto, probar la necesaria validez de las leyes lógicas sería la única forma de refutar al psicologismo siempre y cuando este se encontrara en la situación de poder negar efectivamente las mismas. Sin embargo, ¿qué sucedería si esto no fuese posible, qué acontecería si el pretendido cuestionamiento psicologista de la validez de las leyes lógicas se evidenciara como una ilusión?

6 De hecho, lo máximo que se puede hacer, es apelar a una evidencia, como lo hace Husserl y como, según creo, no le es totalmente extraño a Frege. Mas si admitimos que este apelo, como lo sospecha Føllesdall, introduce un bies subjetivo, entonces no hay salida posible y la objetividad de las leyes lógicas debe ser asumida como un Faktum último. 


\section{LA REFUTACIÓN DEL RELATIVISMO EN FREGE EN LA LÓGICA DE 1897}

\section{El argumento de la Lógica de 1897: introducción}

El texto que vamos a considerar, y que consiste de dos párrafos, puede ser aislado de su contexto, constituyendo en sí mismo una unidad ${ }^{7}$. Pese a su brevedad, el no deja de ofrecer problemas de interpretación que, obviamente, habremos de tener en cuenta. No obstante, es importante que, desde un principio, dejemos en claro que los mencionados problemas no impiden ver en él una clara línea de argumentación en el sentido de una refutación del relativismo, que es lo que en definitiva deseamos poner en primer plano.

\footnotetext{
"Wenn jemand dem widersprechen wollte, dass das Wahre unabhängig von unserer Anerkennung wahr ist, so würde er eben durch seine Behauptung dem was er behauptet widersprechen, in ähnlicher Weise, wie ein Kreter, der sagt, dass alle Kreter lögen.

Wenn nämlich etwas nur für den wahr wäre, der es für wahr hielte, so gäbe es keinen Widerspruch zwischen den Meinungen verschiedener Menschen. Jemand, der diese Meinung hätte, dürfte also folgerichtigt gar nicht der entgegegengesetzten widersprechen, er müsste dem Grundsatz huldigen: non disputandum est. Er könnte im gewöhnlichen Sinne gar nichts behaupten, und wenn er es der Form nach täte, so hätte das doch nur den Wert einer Interjektion; d.h., der Äusserung eines seelischen Zustandes oder Vorganges, der mit einem solchen Zustande oder Vorgange bei einem anderen Menschen nicht im Widerspruch stehen könnte. Und diesen Wert hätte dann auch seine Behauptung, dass etwas nur durch unsere Anerkennung und für uns wahr wäre. Wenn diese Meinung wahr wäre, so wäre der Anspruch unhaltbar, dass die eigene Meinung auch bei anderen grösseres Recht habe, als die entegegensetzte. Eine Meinung, die diesen Anspruch erhöbe, wäre unberechtigt; das hiesse aber jede Meinung im gewöhnlichen Sinne des Wortes wäre unberechtigt, also auch die von uns bekämpfte; es gäbe keine Wissenschaft, es gabe keinen Irrtum, keine Berichtigung des Irrtums, es gäbe eigentlich nichts Wahres im gewöhnlichen Sinne des Wortes. Mit diesem hängt die hier betonte Unabhängigkeit von unserer Anerkennung so enge zusammen, dass sie nicht davon getrennt werden kann. Wenn jemand die hier bekämpfte Meinung ernst und ehrlich verteidigte, so bliebe nur übrig, annehmen, dass er mit dem Worte "wahr" einen anderen Sinn verbände". (L(1897), 45-46.
} 


\section{Primera lectura del primer párrafo}

El texto se mueve inicialmente en el marco de una contraposición entre dos tesis, el absolutismo y el relativismo ${ }^{8}$. El punto de discrepancia entre ambas es que, según la primera, existe una verdad independiente del hecho de ser conocida, en tanto que, según la segunda, toda verdad depende en cuanto tal del hecho de ser conocida. El objetivo de Frege es construir un argumento que refute la segunda como medio de afirmar la primera.

El primer paso, contenido en el primer párrafo, comienza observando que si alguien pretende contradecir a aquel que afirma que la verdad es independiente de nuestro reconocimiento, entonces habrá - a través de su afirmación - de contradecir lo que el afirma, del mismo modo que un cretense que dice que todos los cretenses mienten.

Podemos ofrecer diversas lecturas de este pasaje, según como entendamos la afirmación y la contradicción a la cual se hace referencia.

En una primera lectura, el argumento ofrecido por Frege parece no ser otra cosa que una variación de posturas clásicas. El núcleo del argumento se concentra en el hecho de que la afirmación de la tesis relativista contradice el contenido de esta tesis, o sea, que toda verdad es relativa. Ahora, ¿en qué consiste precisamente la contradicción? Observemos que Frege no está diciendo, sin más, que la tesis relativista es auto-contradictoria, sino que la pretensión de afirmar la misma la contradice. ¿Por qué? Porque afirmar la tesis, "toda verdad es relativa", implica elevar una pretensión de verdad que no es relativa. Quien afirma que la verdad no es independiente de su reconocimiento, ya por el mismo hecho de afirmar esto, contradice su propia afirmación, pues al menos esta verdad pretende ser independiente de su ser reconocida. Leído el texto de esta forma, no es difícil entender el porqué Frege ve aquí una analogía con la

\footnotetext{
Quizás no esté de mas observar, que hemos tomado el argumento fregueano como una refutación del psicologismo, aun cuando relativismo y psicologismo no son sin mas idénticos. Que el psicologismo implica el relativismo, esto no es propiamente un problema y hay base suficiente en los textos para mantener esta asimilación. Una otra cuestión es que, para Frege, pueden existir modalidades de relativismo que no son propiamente psicologistas, como, por ejemplo, el historicisimo (Véase en tal sentido GA,7(VI,VII) y RC, 100). Una identificación ilegitima de historicismo y psicologismo se encuentra en Carl: Frege Philosophie der Sprache, p. 49; una diferenciación correcta, en Rosado Haddock: A critical Introduction to the Philosophy of Frege, p. 18.
} 
paradoja del mentiroso. Así como el cretense, al afirmar que todo cretense es mentiroso, se contradice en cuanto, si está efectuando una afirmación legítima, está pretendiendo decir una verdad, de la misma manera, el relativista se contradice en cuanto, si esta efectuando una afirmación legítima, está levantando una aspiración de verdad que niega el relativismo9

\section{Segunda lectura del primer párrafo}

Esta primera lectura propuesta implica concebir el primer párrafo como un argumento auto- subsistente, $\mathrm{y}$, de esta forma, dejarlo inconexo con el segundo. Esta situación varía en el caso de una segunda lectura posible que, como veremos, permite salvaguardar tal vinculación al mantenerse más cercana de la literalidad del texto.

1. El absolutista afirma: "lo que es verdadero, es verdadero independientemente de nuestro reconocimiento".

2. El relativista intenta contradecirlo. Al hacerlo, pasa a afirmar: "es falso, que lo que es verdadero, es verdadero independientemente de nuestro conocimiento".

3. Obsérvese que en este caso, a diferencia del anterior, lo afirmado por el relativista no es la tesis (positiva), "toda verdad es relativa a su ser reconocida", sino la tesis (negativa), "es falso, que toda verdad es independiente de su ser reconocida".

4. Ahora, el relativista, mediante su afirmación contradice lo afirmado. Siendo diferente lo afirmado en este caso, también lo será el modo en que se fija la contradicción. Si seguimos la primera lectura, y entendemos lo afirmado como la tesis relativista, la contradicción se da entre el carácter absoluto de la afirmación y el contenido relativo de lo afirmado. Mas, si seguimos la literalidad del texto, lo afirmado por el relativista no es propiamente su tesis relativista, sino su negación de la tesis absolutista.

9 Esta lectura encuentra apoyo en la tesis que Frege habrá de defender unas páginas mas adelante, a saber, que toda afirmación implica una aspiración de verdad: "Wer etwas für wahr hält, und die psychologischen Logiker werden doch wenigstens ihre eigenen Einstellungen für wahr halten, erkennt damit etwas an, was wahr ist." L(1897), 66. 
5. Por lo tanto, el acento no reside en que el relativista se contradice cuando afirma su propia tesis, sino en que se contradice cuanto intenta contradecir al absolutista. Su contradicción está presente en la tesis, "es falso, que toda verdad es independiente de su ser conocida".

6. Ahora, ¿por qué hay aquí una contradicción? Simplemente, porque al afirmar que es falso aquello que el absolutista afirma, el relativista está diciendo algo que no pretende ser relativo, sino absoluto. O sea, el relativista se contradice porque al pretender contradecir al absolutista, afirma que hay algo falso independientemente de su ser reconocido como tal.

7. Lo que queda implícito, y que es lo único que podría salvar al relativista de caer en una contradicción, es que la única posición coherente con su principio sería la de abstenerse de pretender refutar al absolutista (y a cualquier otra tesis). $O$ sea el relativista consecuente no puede pretender contradecir nada; en la medida en que lo intenta, él se contradice consigo mismo. El relativista se contradice al pretender contradecir ${ }^{10}$.

8. Esta línea de interpretación, recibe un fuerte sustento en el texto subsiguiente. En efecto, en el caso de esta lectura, hay una clara continuidad entre el primer y el segundo párrafo, y esa continuidad está dada por el hecho de que, desde el punto de vista de un relativista consecuente, no puede haber contradicción alguna de opiniones ni, por lo tanto, intentos de refutación.

9. Sin embargo, todavía falta un último punto a ser clarificado y es el paralelo con la paradoja del mentiroso. En esta segunda interpretación, hay una diferencia entre la situación del mentiroso y la del relativista, pues el mentiroso se contradice al pretender afirmar, el relativista se contradice al pretender contradecir.

10 Siendo más explícitos, diríamos que el relativismo se ve enfrentado a una alternativa sin salida, o acepta su pretensión absoluta, y en este caso se contradice, o acepta que él mismo es una verdad relativa y, entonces, no puede pretender contradecir la tesis absolutista. Para un relativista consecuente su tesis es tan relativa como la del absolutista. En la primera lectura se explora la primera alternativa; en la segunda lectura, la segunda alternativa. 


\section{Análisis de la primera parte del segundo párrafo}

Veamos ahora el recorrido argumentativo del segundo párrafo.

1. Si el relativista tuviera razón, si la verdad dependiese de su ser reconocida, o sea, si algo sólo fuese verdadero para el que lo toma por verdadero, entonces no podría existir propiamente una contradicción entre las opiniones de diferentes individuos. Supongamos que un individuo afirma A y otro - A. El principio de contradicción exige, que sólo una de esas opiniones sea verdadera. No obstante, si, según la hipótesis, la verdad de cada una de esas proposiciones depende de que un individuo la tenga por verdadera, entonces, en principio, es posible que ambas sean verdaderas.

2. Mas, si no hay posibilidad de contradicción, no hay posibilidad de disputa, o sea, de contraponer opiniones opuestas. El relativista debe aceptar la máxima, non disputandum est.

3. Ahora, si hasta aquí nos hemos mantenido en lo que de un modo u otro ya se encuentra implícito en el primer párrafo (de acuerdo con nuestra segunda lectura), un avance significativo, que confirma el recorrido anterior, se da en un tercer y nuevo paso: donde no hay posibilidad ni de contradicción ni de disputa, no se puede decir, en el sentido usual, que se está afirmando algo. Para que tenga sentido decir que algo está siendo afirmado, tiene que tener sentido decir que ese mismo algo puede ser negado por otro algo. En suma, el relativismo torna toda afirmación imposible porque niega las condiciones de posibilidad de una afirmación. En el marco de un relativismo consecuente, es inviable hacer cualquier afirmación, sea del tipo que sea.

4. Si el relativismo anula las condiciones de posibilidad de toda afirmación y, en consecuencia, no puede propiamente afirmar nada, todas sus manifestaciones que, por su forma, se asemejan a afirmaciones, no poseen otro valor que el de meras interjecciones, o sea, ellas son simplemente la expresión de un estado interno. Ahora, estados o procesos anímicos de un individuo no son cosas que puedan estar en relación de contradicción con estados o procesos 
anímicos de otros individuos. Dos meras interjecciones no pueden contradecirse.

5. Si, suponiendo como válido el punto de vista del relativista, se llega a la conclusión de que en el relativismo no puede haber propiamente afirmaciones, sino meras interjecciones, esto termina valiendo para la propia tesis relativista: o sea: la tesis que dice que toda verdad es relativa no es una tesis auténtica, sino una tesis aparente, pues en realidad en ella no se está diciendo propiamente nada, sino tan sólo dando expresión a un estado interno ${ }^{11}$.

6. Dicho de otra forma: la argumentación de Frege no conduce propiamente a la negación de la tesis relativista o a mostrar que ella es falsa, sino que ella está dirigida, mediante una explicitación de aquello que en el relativismo se supone, a mostrar que éste se autodisuelve, que si tiene razón, entonces, justamente por ello, no puede ser propiamente afirmado.

\section{Tercera relectura del primer párrafo}

Llegados a este punto, se abre una nueva posibilidad de relectura del primer párrafo analizado que, en alguna medida, relativiza las dos lecturas anteriormente propuestas pasando a segundo plano sus diferencias y situando en el foco una nueva cuestión.

11 En las GGA de 1893 hay un pasaje que recuerda el que venimos considerando; un análisis más minucioso, no obstante, muestra que la similitud entre ambos es superficial y, en el fondo tan sólo aparente. En 1893 Frege efectúa sus consideraciones en el marco de su crítica del idealismo, asimila el acto de designación (y no de afirmación) a una interjeccion y, por sobre todo, en ningún momento sugiere que el idealismo o relativismo no sea una tesis auténtica sino una interjección. Compárese Thomas Ricketts: Objectivity and Objecthood, p. 70-71. De lo ya expuesto es claro que sólo aceptamos la tesis de Ricketts con importantes restricciones. La más importante de las mismas, no obstante, no ha sido mencionada, a saber, la pretensión de Ricketts de reducir el problema del psicologismo en Frege al punto indicado. La totalidad de la cuestión merecería un tratamiento detallado que no podemos ofrecer en el marco del presente artículo. 
1. El absolutista afirma que el ser verdadero es independiente del ser considerado como verdadero. El relativista pretende contradecirlo, sea afirmando la tesis relativista, sea negando la absolutista.

2. Ahora, Frege contrapone la afirmación a lo afirmado. Lo afirmado es una tesis o proposición; la afirmación no es una tesis, sino el mismo acto de afirmar ${ }^{12}$ y éste, considerado no como acto de afirmar algo específico, sino como el acto de afirmar en cuanto tal ${ }^{13}$.

3. Ahora, ¿en qué consiste la contradicción? Normalmente una contradicción se da entre dos enunciados. No obstante, la "contradicción" de la cual se trata aquí no es entre algo afirmado y otro algo afirmado, sino entre el acto de afirmar en cuanto tal (o el acto de contradecir) y el contenido afirmado. Pero, ¿en qué sentido un acto puede contradecir una proposición? Si seguimos el camino recorrido en el segundo párrafo, se nos ofrece una posibilidad de respuesta a esta pregunta. En él, el análisis del contenido afirmado evidenciaba la imposibilidad de una afirmación (la anulaba, la hacía imposible). Algo similar es lo que ahora se nos esta diciendo. Los supuestos que dan sentido al acto de afirmar, contradicen el contenido afirmado. Dicho de otra forma, el acto de afirmar (en cuanto acto de afirmar en sí, y no en cuanto acto de afirmar ese contenido específico) contradice el contenido específico afirmado, pues éste, en su desarrollo, implica supuestos que privan al acto de afirmar de su sentido.

La interpretación que acabamos de ofrecer presenta algunas ventajas con respecto a las expuestas primeramente, aún cuando, ciertamente, no está exenta de toda dificultad. Si nuestra tercera propuesta es correcta, entonces, el primer párrafo viene a efectuar una primera formulación - no libre de todo equívoco - que es explicitada en el comienzo del segundo párrafo. Lo que en el primer párrafo aparece como un único

12 Obviamente, la "afirmación" no es propiamente un acto empirico, sino un acto lógico.

13 Esta distinción es importante pues la contradicción no debe ser establecida, como veremos, entre afirmar un algo y ese algo afirmado, sino entre el acto de afirmar en cuanto tal, y el contenido afirmado. 
paso, se desdobla en dos en el segundo. En tanto en el primer párrafo se establece la contradicción entre la afirmación y el contenido afirmado, en el segundo, esta contradicción es explicitada al enumerarse los momentos intermedios que vinculan las dos instancias, o sea, el hecho de que el concepto de afirmación supone la posibilidad de contradicción y disputa, en tanto que ésta es anulada por la tesis relativista.

dejadas de lado.

Sin embargo, hay dos dificultades que no pueden ser

1. En primer lugar, en tanto en el segundo párrafo, la contradicción es fijada entre el contenido afirmado y el acto de afirmar, en el primero, la contradicción es la inversa, a saber, entre el acto de afirmar y el contenido afirmado. Esta diversidad en el orden puede ser entendida como una diferencia de acento y, esta diferencia, a su vez, puede hacer más aceptable la primera interpretación. En efecto, en tal caso, no es difícil entender por qué el hecho de afirmar, en cuanto eleva una pretensión absoluta, contradice el contenido afirmado, según el cual la verdad es relativa.

2. En segundo lugar, en el texto en cuestión, Frege establece un paralelo entre la situación que el pretende describir y la paradoja del mentiroso. Ahora, no hay dificultad alguna en establecer en qué consiste este paralelo, en el caso de la primera interpretación. Pero ¿y en la tercera? En principio sigue existiendo un punto de contacto. También el mentiroso anula, mediante su afirmación la condición de posibilidad de su afirmación. No obstante, obsérvese, el mentiroso no anula la condición de posibilidad de toda afirmación, sino de esa afirmación específica y, por ello, lo que el mentiroso afirma no deja de ser una verdadera tesis.

No obstante, sea cual fuera la relación entre el primer y el segundo párrafo, la lectura del segundo se mantiene de por sí, y ella contiene un modo de argumentación que conviene no perder de vista. Lo que aquí le interesa a Frege no es simplemente denunciar una contradicción en el relativismo, sino explicitar lo que realmente implica y, de esta forma, conducirlo a su autodisolución. La tesis relativista se auto anula, pues ella implica negar las condiciones de posibilidad de toda afirmación y, por lo 
tanto, de la afirmación de sí misma. Esto significa que el relativista no dice propiamente nada; es sólo la apariencia de una tesis, pero no una tesis genuina.

\section{Análisis de la segunda parte del segundo párrafo}

Con lo expuesto hasta ahora, el análisis del segundo párrafo no está completo, pues faltan aún importantes pasajes en los cuales Frege introduce el concepto de verdad en el marco de la polémica antirelativista.

$\mathrm{Si}$ el relativismo fuese verdadero, entonces toda opinión que aspirase a valer para otros, sería injustificada. Obviamente, esto valdría para las propias opiniones del relativista: la pretensión de que la propia tesis tuviese un derecho mayor que la opuesta sería insostenible. En consecuencia, el relativista no podría disputar nada y tendría que aceptar todos los puntos de vista, inclusive los opuestos al suyo. Con esto, se anula la propia idea de fundamentación o justificación de una afirmación. Si todas las opiniones tienen el mismo derecho, todas las opiniones son igualmente infundadas (unberechtigt). Pero, si esto fuera así, no habría ni ciencia, ni error, ni corrección del error. En suma, lo que es más importante y en cierto sentido resume todo lo anterior: no habría nada verdadero en el sentido usual del término.

A esta última tesis debemos dedicar atención especial. El eje de la argumentación fregueana, en los últimos pasajes, gira alrededor de la postulación de una idea de verdad absoluta, sobre la cual Frege ya ha insistido en otros textos. El concepto de verdad supone analíticamente el de la independencia de su ser reconocido como tal y, por lo tanto, uno no puede ser separado del otro. Sin embargo, si la tesis relativista fuera verdadera, entonces la verdad dependería de su ser conocida y, en consecuencia, o bien se acepta que no hay nada verdadero en el sentido normal del término, o simplemente se asume que se altera este sentido y se usa el término verdad en un sentido diferente.

Frege usa aquí una estrategia muy coherente con sus convicciones, a saber: partiendo de la idea de que la verdad es siempre independiente de todo sujeto cognoscente, cuestionar la idea relativista de verdad como alterando el auténtico concepto de la misma. Este argumento se auto sostiene y puede ser usado con independencia del recorrido anterior y así Frege efectivamente lo hace en otras ocasiones (GGA, XVI; L(187991),5). La pregunta es, no obstante, ¿cómo él se integra en el actual contexto? 
El concepto de verdad no es introducido abruptamente, sino por medio de una gradación de conceptos. Toda afirmación exige al menos la posibilidad de una justificación. El relativista tira todo sentido a la idea de justificación de una afirmación y, por lo tanto, en última instancia, tanto a la idea de error como a la idea de verdad.

Frege menciona como elemento definitorio del concepto de verdad su absoluta independencia de todo ser reconocida como tal. No obstante, éste no es el único elemento analíticamente contenido en el concepto de verdad. En otros textos aparecen expresamente otros elementos, como la no relación a condiciones de espacio y tiempo (GGA, XVI-XVII). Mas, ¿no podríamos decir lo mismo de conceptos tales como afirmación y no contradicción? Si el concepto de afirmación no tiene sentido sin la posibilidad de contradicción, ¿acaso la tiene sin una referencia al menos implícita a una aspiración de verdad? ${ }^{14} \mathrm{Y}$, asimismo, ¿no podríamos decir que la no contradicción es una exigencia establecida analíticamente por el propio concepto de verdad?

Frege pretende que el relativismo se encuentra en una disyuntiva: o acepta el concepto de verdad en su sentido usual, y en tal caso tiene que admitir que según el no hay ninguna verdad, o muda el sentido usual del término. Pero, ¿no es esta una concesión en extremo generosa para con el oponente? Si el relativismo pretende usar la palabra verdad en otro sentido, ello sólo podrá ser concedido si el es capaz de explicitar en cuál. Pero, ¿por qué conceder al relativismo que puede dar otro sentido a la palabra verdad? ¿Por qué no decir que, en realidad, al pretender tomar la palabra verdad en otro sentido, el relativismo priva a la palabra verdad de todo sentido? Esto sería plenamente coherente con la afirmación que el relativismo torna imposible la posibilidad de toda afirmación. El caso de la verdad no es diferente del caso de la afirmación. El relativismo puede continuar hablando de afirmación y de verdad, pero esto es una cuestión meramente nominal. En realidad, el suprime las condiciones de posibilidad de toda verdad, así como suprime las condiciones de posibilidad de toda afirmación.

14 Véase nota 9. 


\section{LA CRÍTICA DEL RELATIVISMO EN HUSSERL}

\section{Consideración preliminar sobre la refutación husserliana del relativismo: el relativismo niega las condiciones de posibilidad de una teoría y por ello es un contrasentido (widersinnig)}

La refutación husserliana del psicologismo se efectúa sobre la forma de una crítica del relativismo (LU,I,§38, p. 123). La crítica del relativismo busca mostrar que éste, en última instancia, conduce el escepticismo. Ahora, para precisar esta tesis, debemos tener en cuenta el sentido particular en que Husserl define el escepticismo y la delimitación que efectúa de este escepticismo, que ahora critica, con otras modalidades del mismo, por ejemplo, el metafísico (LU,I,§33, p.112). El escepticismo del que se ocupa Husserl es una propiedad de ciertas teorías. Una teoría es escéptica si contradice las condiciones de posibilidad de toda teoría (LU,I, §32, p. 110). Estas condiciones pueden ser clasificadas en subjetivas y objetivas (o noéticas y lógicas) (LU,I,§65, p. 236). Son condiciones noéticas aquellas que se fundan de modo puramente analítico en el concepto del conocer como, por ejemplo, la idea de que el sujeto no meramente afirma algo, sino que tiene un fundamento que legitima esta afirmación (y el cual, en última instancia, se encuentra en la evidencia). Comprendemos por condiciones objetivas, a todas las leyes que se fundan puramente en el concepto de teoría y que constituyen de modo esencial el concepto de unidad teórica. Ellas derivan de los conceptos básicos de una teoría tales como, por ejemplo, verdad, proposición, objeto, propiedad o relación (LU,I,§32, p.111). Una teoría que, en su contenido, va contra las leyes sin las cuales el propio concepto de teoría no posee ningún sentido, se anula a sí misma (LU,I,§32, p.112). Una teoría que contradice a las condiciones de posibilidad de toda teoría, es un contrasentido. En consecuencia, pertenece al propio concepto de una teoría escéptica, el ser un contrasentido (LU,I,§32, p.112). Dados los elementos anteriores, resumamos nuestra conclusión diciendo: toda teoría relativista es escéptica porque ella es un contrasentido, o sea, ella contradice las condiciones de posibilidad de una teoría. 


\section{El relativismo niega las condiciones de posibilidad de toda afirmación}

Husserl refuta al relativismo en cuanto evidencia que de él se sigue necesariamente el escepticismo. Éste es definido en base a la noción de teoría. Mas, una teoría se compone de enunciados y de una unidad sistemática de los mismos. Esto permite distinguir, por lo menos, entre dos tipos diversos de condiciones de posibilidad de una teoría. Ellas comprenden, por un lado, las condiciones de la unidad sistemática (primariamente, la relación de fundamento y consecuencia), por otro, las condiciones de posibilidad de los enunciados.

Si Husserl define el escepticismo por relación al concepto de teoría, su definición vale también, en particular, con respecto a los enunciados de los cuales una teoría se compone. Husserl fija, pues, el concepto de contrasentido no sólo por relación a las teorías como un todo, sino también por relación a sus enunciados. Refiriéndose al relativismo individual, Husserl observa que las teorías escépticas son contrasentidos, pues el contenido de sus afirmaciones niega lo que pertenece al contenido de toda afirmación, y que, por lo tanto, no puede ser separado de ellas (LU,I,§35, p. 116).

Ahora, dado que la doctrina anterior aparece en el contexto de la crítica al relativismo individual, podría argumentarse, que ella no vale para el relativismo específico. Por tal motivo, es importante observar que, con diferentes palabras, Husserl vuelve a repetir expresamente esta doctrina por referencia al relativismo específico. También con respecto a éste se encuentra una contradicción evidente, aun cuando implícita, entre el sentido de sus tesis y aquello que no es separable con sentido (sinngemäss) de ninguna tesis (LU,I,§36, p.116).

En una dirección similar ya se había manifestado Husserl, inclusive antes de introducir la distinción entre relativismo individual y específico. Husserl diferencia tres formas de infracciones (Verstösse) contra las leyes de una teoría: en los supuestos de la misma, en la forma de su combinación teórica y, finalmente, en las tesis probadas (LU,I,§32, p. 112). Ahora bien, el infringir las leyes de una teoría se opera del modo más patente (offenbar), cuando pertenece al sentido de las tesis teóricas el negar las leyes de las cuales depende la posibilidad de toda tesis y de toda fundamentación de una tesis (LU,I,§32, p. 112).

Dado los textos anteriores, parecería pues que, en principio, toda afirmación relativista o, al menos, la tesis relativista en cuanto tal, es un contrasentido por contradecir, por medio de aquello que ella afirma, las condiciones de toda afirmación. 


\section{Las condiciones básicas de una afirmación}

Si el relativismo es un contrasentido porque en el contenido de sus afirmaciones niega lo que pertenece al contenido de toda afirmación, resta aún determinar este segundo concepto, o sea, especificar cuáles son las condiciones de posibilidad de toda afirmación. Ahora, es esencial a toda afirmación el ser verdadera o falsa (LU,I,§36, p.117). Si queremos explicitar en qué consisten las condiciones mencionadas, tenemos entonces que explicitar en qué consiste el concepto de verdad.

1. En el concepto de verdad están analíticamente contenidos los principios lógicos (LU,I,§36,p.118); en consecuencia, el respeto a los mismos es condición de toda afirmación. Entre estos principios Husserl menciona expresamente dos, el de no contradicción y el de tercero excluido, otorgando particular énfasis al primero. El relativista (tanto individual (LU,I,§35, p.115) como específico (LU,I,§36, p.117)) transgrede el principio de contradicción. Frente a la posible contra-réplica, de que este principio, en su formula usual, podría estar incompleto, y que en su formula plena, incluiría una referencia a un sujeto individual o a una especie, Husserl observa, que es simplemente un contrasentido hablar de algo que es verdadero para este o para aquel individuo.

2. Si el relativismo tuviese razón, la verdad dependería de un hecho, a saber, de la constitución de la especie y, dado que de un hecho sólo puede depender otro hecho, la verdad sería un hecho. La verdad, sin embargo, no es un hecho. En efecto, ella no posee las propiedades que caracterizan a los hechos: ella no es individual, no está determinada temporalmente ni puede entrar en relaciones de causa o efecto (LU,I,§36,p.119) $)^{15}$.

15 Husserl no menciona expresamente la falta de determinacion espacial; pero no hay una dificultad de principio de tomarla también en cuenta, a no ser, el que no todos los hechos son espaciales, sino que algunos son exclusivamente temporales. 
3. Lo que es verdadero es verdadero en sí, verdadero en sentido absoluto; la verdad es siempre una, sea para hombres, para ángeles o para dioses (LU,I,§36, p. 117).

4. Si el relativista no acepta las tres condiciones indicadas como inherentes al concepto de verdad y, no obstante, insiste en continuar hablando de verdadero y falso, entonces ello sólo es posible porque él altera el sentido de los términos, transformando así la cuestión filosóficamente relevante en una meramente nominal. Si se altera el sentido de la palabra verdad, entonces ella puede ser atribuida como cualidad simplemente a cualquier cosa como, por ejemplo, a árboles. En tal caso, es obvio que tales objetos no tendrían aquellas propiedades que han sido determinadas como inherentes a la verdad y, por tanto, entre otras cosas, podría argumentarse que para ellos los principios lógicos no contienen validez necesaria. Y algo por el estilo es lo que efectivamente hace el relativista. Sin embargo, él no reconoce abiertamente este decisivo paso y prefiere mantenerse en la ambivalencia, o sea, al mismo tiempo que, por un lado, de hecho elimina el significado del concepto de verdad, por otro, mantiene la pretensión de continuar hablando de verdad en el sentido determinado por los principios lógicos (LU,I,§36, p. 118).

\section{¿Son contrasentidos auténticos enunciados?}

La noción de contrasentido es empleada por Husserl en dos momentos diferentes de las "Investigaciones lógicas", a saber, en los ya mencionados pasajes de los Prolegómenos y en la $4^{\text {a }}$. Investigación, en donde se la contrapone a la noción de sin sentido (Unsinn). Si nos atenemos a la $4^{a}$. Investigación, entonces está fuera de duda que contrasentidos poseen sentido y, eventualmente, constituyen auténticos enunciados. Ahora, la definición de contrasentido dada en los Prolegómenos, torna difícil mantener esta tesis. Si definimos contrasentidos como negando las condiciones de posibilidad de toda afirmación, ¿cómo, no obstante, afirmar que ellos son auténticas tesis? 
Y, no obstante, no hay absolutamente nada en el texto de Husserl que permita extraer la conclusión de que la tesis relativista no sea una auténtica tesis. Quizás lo que más se acerca a levantar, por lo menos, tal duda es la consideración, a la cual ya nos hemos referido que, al alterar el sentido de verdad, el relativista puede atribuir la cualidad de ser verdadero a cualquier cosa, como por ejemplo, a los árboles.

\section{Un nuevo tipo de afirmaciones que son contrasentidos: el relativismo niega el contenido de las categorías de significación (Bedeutungskategorien)}

De acuerdo a lo expuesto hasta ahora, se sigue que Husserl define el concepto de teorías que son contrasentidos, como teorías que contradicen las condiciones de posibilidad de toda teoría, y afirmaciones que son contrasentidos, como afirmaciones que no cumplen con las condiciones de posibilidad de toda afirmación. Si nos detenemos aquí, entonces podemos afirmar, sin restricción, que toda afirmación que es un contrasentido, lo es por no cumplir con las condiciones de posibilidad de toda afirmación. No obstante, en el $\S 37$ Husserl introduce un nuevo concepto de afirmaciones que son contrasentidos. Tenemos entonces que fijar este nuevo concepto y, a partir de ello, ver como se relaciona con el primeramente considerado.

Husserl comienza el referido § 37 distinguiendo dos significados del término relativismo, uno amplio y otro restringido. En qué consista precisamente esta distinción, cuál sea el fin de la misma y, eventualmente, por qué ella debe ser introducida justo ahora, no nos es dicho. Lo único que se indica es que el relativismo, en sentido amplio, consiste en toda teoría que, de un modo u otro, deriva principios de hechos y que las formas de relativismo distinguidas hasta ahora (o sea, el relativismo individual y específico) son casos especiales del relativismo en este sentido más amplio (o sea, que es común a ambos el derivar principios de hechos) (LU,I,§37, p.122).

Una vez establecido el concepto de un relativismo en sentido amplio, Husserl pasa a ofrecer una nueva definición de afirmaciones que son contrasentidos. Según esta nueva definición una afirmación es un contrasentido, o sea, se auto anula, si su sentido contradice aquello que es exigido por las categorías de significación que ella efectivamente emplea o, 
al menos, supone (LU,§37,p.123). Dicho de otra forma: en toda afirmación, o los conceptos empleados corresponden a tipos de categorías de significación o, eventualmente, son ellos mismos categorías de significación, cada una de las cuales posee una legalidad propia, tal que ella permite y no permite ciertas combinaciones con otras ${ }^{16}$. Afirmaciones que son contrasentidos se producen cuando se combinan en un enunciado conceptos que corresponden a categorías de significación que son incompatibles. Es justamente esto lo que acontece en el caso de afirmaciones que, de un modo u otro, reducen principios lógicos a hechos (LU,I,§37,p. 123). Una tal reducción supone una violación tanto del sentido del concepto de principio, como del de hecho.

Esta nueva definición de afirmaciones que son contrasentidos es exactamente paralela a la de teorías que son contrasentidos, constituyendo en realidad una aplicación de este segundo concepto al primero como caso particular. En ambos casos se trata de la contradicción con las leyes derivadas de los conceptos básicos de una teoría o categorías de significación.

Clarificado el nuevo concepto de afirmaciones que son contrasentidos, procuremos avanzar en el sentido de establecer la relación en que se encuentra el mismo con el primeramente expuesto.

1. El primer punto a ser observado es que Husserl introduce una nueva definición de afirmaciones que son contrasentidos sin preocuparse en ningún momento por establecer la relación en la cual ella se encuentra con la ya aportada. Inútilmente se buscará en el texto una indicación esclarecedora a ese respecto.

2. En principio, parece claro que se trata de dos conceptos de afirmaciones que son contrasentidos, que son diferentes e independientes entre sí.

3. Afirmaciones que son contrasentidos en el primer sentido suponen una contradicción entre el contenido afirmado y las condiciones de toda afirmación; afirmaciones que son contrasentidos en el segundo sentido, no contradicen las posibilidades de toda afirmación, sino que contradicen las condiciones de posibilidad de esa afirmación específica.

${ }_{16}$ La consideración de lo expuesto por Husserl em la $4^{\mathrm{a}}$ investigación ofrece uma clarificación de lo dicho ahora. Ella, sin embargo, no deja de plantear también dificultades. Según la 4a. investigación, la combinación de categorías de significación incompatibles produce el sinsentido, no el contrasentido. 
4. Toda afirmación que es un contrasentido en el primer sentido, remite en última instancia a una contradicción producida por categorías de significación; estas categorías de significación no son cualesquiera, sino concretamente verdad y todo lo que ella implica. En consecuencia, toda afirmación que es un contrasentido en el primer sentido, implica ya al menos un caso particular de afirmación que es un contrasentido en el segundo sentido.

5. Una afirmación que es un contrasentido en el segundo sentido, no necesariamente implica una afirmación que es un contrasentido en el primer sentido.

Si tomamos en cuenta que estamos frentes a dos sentidos diferentes de afirmaciones que son contrasentidos, no podemos ahora decir sin más que toda afirmación que es un contrasentido lo es porque anula las condiciones de toda afirmación y, en consecuencia, no podemos decir sin más que todo relativismo es un contrasentido, porque en el contenido de su afirmación auto-anula las condiciones de posibilidad de toda afirmación. La impresión que se obtiene en un comienzo, a saber, que la primera forma de contrasentido era válida para todas las afirmaciones relativistas, debe ser ahora revisada.

\section{CONCLUSIÓN: comparación de la refutación del relativismo en frege y husserl}

Nuestro punto de partida fue la tesis de Føllesdall, vigente hasta nuestros días, de que existe una diferencia esencial en la crítica al psicologismo de Frege y Husserl pues en cuanto según el primero, el psicologismo no es refutable, según el segundo sí lo es. De lo que llevamos expuesto hasta ahora podemos concluir:

1. Existen en Frege de hecho intentos de refutación del psicologismo. Con uno de ellos nos hemos ocupado en las líneas que anteceden.

2. El consiste básicamente en evidenciar que el relativismo contradice las condiciones de posibilidad de toda afirmación. 
3. Tal estrategia argumentativa encuentra un paralelo en una de las líneas de la refutación husserliana del psicologismo: también aquí el punto central consiste en evidenciar que el relativismo contradice las condiciones de posibilidad de toda afirmación.

4. El paralelo constatado, no obstante, va más allá de la tesis y también se refiere a las razones en que se sustenta la misma: tanto en Frege como en Husserl el relativismo anula las condiciones de posibilidad de toda afirmación porque infringe el principio de contradicción.

5. Si lo anterior es cierto, de ello se sigue que no se puede afirmar coherentemente que existe en Husserl un intento de refutación del psicologismo y no en Frege.

Ahora bien, si es posible establecer un paralelo entre las refutaciones del relativismo en Frege y Husserl, esto no implica, no obstante, afirmar que existe entre ambos una absoluta identidad o desconocer la existencia de puntos de discrepancia.

1. La refutación del relativismo aparece en Husserl en el marco de una serie de conceptos que no están presentes en Frege. Así, esta refutación toma como punto de partida el concepto de teoría, diferencia entre condiciones noéticas y lógicas y entre el relativista individual y específico ${ }^{17}$. Esto, no obstante, no impide traer ambas posiciones a un denominador común.

2. Husserl caracteriza a los enunciados relativistas como contrasentidos que niegan las condiciones de posibilidad de todo enunciado, pero en ningún momento afirma que no sean auténticos enunciados. Frege, por el contrario, enfoca su crítica exactamente en este punto. No obstante lo anterior,

17 Ni siquiera mencionaríamos este tipo de diferencias si no fuese que algunos autores, como Rossado Hadock (op. cit., p. 32-33), consideran que esta falta de distinciones en Frege constituye una liberalidad imperdonable que deforma las teorías que critica y, todo esto, claro está, por contraposición a Husserl, quien leal en sus críticas, establece las distinciones que son adecuadas a sus oponentes. Confieso no ver la menor relevancia en esta cuestión. Frege sabe muy bien que Erdmann defiende un relativismo específico, como sabe muy bien (y como no lo podía ignorar Husserl), que Erdmann es idealista y, en definitiva, solipsista. El hecho de que individuos de una especie ordenen sus representaciones del mismo modo, no desmiente el hecho de que ellos tengan como sus únicos objetos contenidos inmanentes de sus conciencias y, por lo tanto, ítems privados. 
no se puede pasar por alto que Husserl sospecha que el relativista no sólo altera el sentido del concepto de verdad, sino que lo hace de un modo tal que, en principio, incluso debe ser considerada la posibilidad que aquello a lo cual él atribuye este concepto no sea en absoluto capaz de poseerlo.

3. No todo enunciado relativista es para Husserl un contrasentido por contradecir las condiciones de posibilidad de toda afirmación, sino que existen en él dos conceptos del contrasentido de un enunciado.

4. Husserl basa explícitamente su tesis de que el relativismo contradice las condiciones de toda afirmación, en un análisis del concepto de verdad, uno de cuyos elementos esenciales, es el principio de contradicción. Nada existe en el texto fregueano que contradiga esta vía, pero no es menos claro que, en todo caso, ella permanece en un plano contextual y meramente implícito. El concepto de verdad, de todas formas, es similar ${ }^{18}$.

\section{REFERENCIAS}

CARL, W. Freges philosophie der sprache. Hagen: FernUniversität, 1986.

FØLLESDALL, D. Husserl und Frege: ein beitrag zur beleuchtung der entstehung der phänomenologischen philosophie. Oslo: Aschehoug, 1958.

FREGE, G. Logik. In: GOTTFRIED, G. Schriften zur Logik und Sprachphilosophie. Aus dem Nachlass. 3. Aufl. Hamburg: Meiner, 1990. p. 35-73. Barth, 1893.

Grundgesetze der Arithmetik. Begrifflich abgeleitet. I. Band. Leipzig:

. Die Grundlagen der Arithmetik. Hamburg: Meiner, 1986.

Rezension von H. Cohen: das prinzip der infinitesimal methode und seine geschichte. In: SCHRIFTEN, K. Angelelli. Hildesheim: Olms, 1967. p. 99-102.

18 Esta similitud no excluye que, en una comparación más rigurosa, se deban constatar importantes diferencias. Véase Hanna: Logical cognition. Husserls Prolegomena and the Truth in Psychologism. 
FRÖHLICH, G. Ein neuer Psychologismus. Würzburg: Konigshausen Neumann, 2000.

HUSSERL, E. Logische Untersuchungen. 6. Aufl. Tübingen: Max Niemeyer Verlag, 1980.

KUSCH, M. Psychologism: a case study in the sociology of philosophical knowledge. London: New York, 1995.

MEILAND, J. Psychologism in logic: Husserl's critique. Inquiry, v. 19, p. 325-339, 1976.

MOHANTY, J. N. Husserl and Frege. Bloomington: Indiana University Press, 1982.

SUKALE, M. Comparative studies in phenomenology. The Hague: Martinus Nijjhof, 1976.

Denken, Sprechen, Wissen. Tübingen: J. C. B. Mohr, 1988.

Sprachlogik. Sechs Studien zur Logik. Sprachphilosophie und Wissenschaftstheorie. Frankfurt: Peter Lang, 1988.

RICKETTS, T. Objectivity and Objecthood: Frege's Metaphysics of Judgment. In: HAAPARANTA, L.; HINTIKKA, J. (Ed). Frege Synthesized: Essays on the Philosophical and Foundational work of Gottlob Frege. Dordrech: Reidel, 1986. p. 65-95.

ROSADO HADDOCK, G. E. A critical introduction to the philosophy of Gottlob Frege. Burlington: Ashgate, 2006. 